\title{
Cooperative Advertising Research with Product Pricing
}

\author{
Zheng Wang ${ }^{1}$ \\ ${ }^{1}$ Hefei University of Technology; Hefei, 23000 \\ 346591653@163.com
}

KEYWORDS: Cooperative advertising; pricing; Game

\begin{abstract}
On the supply chain channel of a single manufacturer and single retailer, we research the cooperative advertising expenditures and product pricing. We consider the price into the cooperative advertising decisions, and use the four different games to research the decision to choose the optimal advertising, the optimal pricing and the optimal profit between the manufacturer and retailer, respectively. Through comparative analysis, we know in cooperative game situation, we spend the most on advertising, the lowest price, but the profit is the highest. In the situations of Stackelberg retailer game, we have the manufacturer's maximum profit.
\end{abstract}

\section{Introduction}

In this highly competitive era, cooperation is the choice of the times. Alternative strategies of cooperation between manufacturers and retailers, advertising vertical cooperation between the supply chain means that local manufacturers to retailers advertising subsidies, in order to encourage retailers to do more advertising to increase sales of the product.

Cooperative advertising very early became popular in the market, according to the US White Paper, the nation's cost for cooperative advertising from 2007 to \$ 25 billion, the rapid increase in $2008 \$ 50$ billion. So amazing, advertising expenses to promote theoretical research expenditure for the channel members to participate in an effective program to explore.

Discussion in promotional advertising and brand advertising impact at the same time, the literature also consider the combined effect of pricing and advertising, for example, Xie and Wei (2009) [1] through the establishment of two game model to discuss retail prices, wholesale prices and advertising on the market impact on demand, the study found cooperative game better supply chain coordination, cooperative game to get more channels than non-profits. This paper discusses the four game situation, the co-product pricing and advertising on retailers and manufacturers decisions.

Cooperative Advertising and Pricing consider static situation is relatively small, such as Jorgensen and Zaccour (1999, 2003) [2-3]; Jorgensen, Sigue and Zaccour (2001) [4], the paper presents a dynamic situation, pricing and Collaborative advertising, discuss how to coordinate the supply chain has been maintained, and studied under static situation with cooperative advertising pricing model.

So in four different game situations, consider a manufacturer and a retailer in a static situation on how advertising investment strategy, product pricing how subsidy advertising strategy developed by the manufacturer to the retailer how different strategies for manufacturers, retailers and how it affects the overall channel profits? This is the main content of this paper.

1 , model and underlying assumptions described 
This article is based on a single supply chain system which manufacturers and retailers as a single object, while retailers sell only assume that manufacturers of products, manufacturers only offer products to vendors.

In the literature Yue (2006) [5], Xie and Wei (2009) [1] and so on, based on the need to establish a function $D(p, a, A)$ such as:

$$
D(p, a, A)=D_{0} \cdot g(p) \cdot h(a, A)
$$

Which represents the price is not affected by advertising and sales base; sales representatives in part influenced by the prices; shows the effect of local advertising and national advertising sales.

According to the literature, Yue (2006) [5], Xie and Neyret (2009) [6] and Xie and Wei (2009) [1], assuming that the price model () as follows:

Which $D_{0}$ represents the price is not affected by advertising and sales base; sales $g(p)$ representatives in part influenced by the prices; $h(a, A)$ shows the effect of local advertising $a$ and national advertising $A$ sales.

According to the literature, Yue (2006) [5], Xie and Neyret (2009) [6] and Xie and Wei (2009) [1], assuming that the price model $(g(p))$ as follows:

$$
g(p)=\alpha-\beta p
$$

Which $\alpha>0, \beta>0$ is the sales price of the influencing parameters, the price $p>0$ is zero, since sales can not be negative, we get: $p<\alpha / \beta$

We consider local advertising and national advertising has an impact on sales volume, respectively, according to the literature Karry and Zaccour Modeling (2006) [7], Sigue and Chintagunta (2009) [8], He (2011) [9], we Suppose advertising model ( $h(a, A))$ as follows:

$$
h(a, A)=k_{1} \sqrt{a}+k_{2} \sqrt{A}
$$

It shows the effect of advertising on sales each.

Comprehensive sales formula above we can see:

$$
D(p, a, A)=D_{0}(\alpha-\beta p)\left(k_{1} \sqrt{a}+k_{2} \sqrt{A}\right)
$$

Suppose manufacturers and retailers are seeking to maximize their own profits optimal advertising decisions. Advertising subsidies manufacturer to the retailer offered rate $t, 0<t<1$; we use the index $m, r, m+r$, representing manufacturers, retailers and the overall supply chain. We have established manufacturers, retailers and the overall supply chain model as follows according to the above demand model:

$$
\begin{gathered}
\pi_{m}(w, A, t)=D(w-c)-t a-A \\
\pi_{r}(p, a)=D(p-w-d)-(1-t) a \\
\pi_{m+r}(p, a, A)=D(p-c-d)-a-A
\end{gathered}
$$


Among them $c>0, d>0$ the cost for the manufacturers and retailers $w>0$, wholesale prices.

In this article, we assume that profit is a positive number, so the formulas 5-7 for the following parameters defined:

$$
\pi_{m}>0 \Rightarrow w>c ; \quad \pi_{r}>0 \Rightarrow p>w+d>w ; \quad \pi_{m+r}>0 \Rightarrow p>c+d
$$

We will use literature Xie and Neyret (2009) [6] and SeyedEsfahani et al. (2011) [10] simplified formula approach to the above formula can be simplified as follows:

$$
\begin{gathered}
\alpha^{\prime}=\alpha-\beta(c+d) ; \\
p^{\prime}=\frac{\beta}{\alpha^{\prime}}(p-c-d) \quad ; \quad w^{\prime}=\frac{\beta}{\alpha^{\prime}}(w-c) \\
k_{r}{ }^{\prime}=D_{0} \frac{\left(\alpha^{\prime}\right)^{2}}{\beta} k_{r} ; \quad k_{m}{ }^{\prime}=D_{0} \frac{\left(\alpha^{\prime}\right)^{2}}{\theta} k_{m} \\
p<\frac{\alpha}{\beta} \Leftrightarrow \beta p-\beta(c+d)<\alpha-\beta(c+d) \Leftrightarrow \frac{\beta p-\beta(c+d)}{\alpha-\beta(c+d)}<1 \Leftrightarrow p^{\prime}<1 \\
p>w+d \Leftrightarrow p-(c+d)>w-c \Leftrightarrow p^{\prime}>w^{\prime}
\end{gathered}
$$

By the above discussion, we found that the changed retail price and wholesale price of size relations is defined before the change, which is consistent with the fact that we will be more than an alternative formula is substituted into the formula, you can get:

$$
\begin{gathered}
D^{\prime}\left(p^{\prime}, a, A\right)=\left(1-p^{\prime}\right)\left(k_{r}{ }^{\prime} \sqrt{a}+k_{m}{ }^{\prime} \sqrt{A}\right) \\
\pi_{m}{ }^{\prime}\left(w^{\prime}, A, t\right)=D^{\prime} w^{\prime}-t a-A \\
\pi_{r}{ }^{\prime}\left(p^{\prime}, a\right)=D^{\prime}\left(p^{\prime}-w^{\prime}\right)-(1-t) a \\
\pi_{m+r}\left(p^{\prime}, a, A\right)=D^{\prime} p^{\prime}-a-A
\end{gathered}
$$

\section{Decision Model under Four Different Scenarios}

In the supply chain system, the parties are seeking to maximize their profit target, whereby paper constructs between manufacturers and retailers Nash non-cooperative game, as the leading manufacturer Stackelberg game, as the leading retailer and cooperative Stackelberg game Game.

\section{A. Nash Non-cooperative Game}

Nash game refers to the manufacturers and retailers at the same time to make a decision in favor of its own profit maximization game. In this case the manufacturer does not provide advertising subsidies to retailers, namely, the objective function becomes:

$$
\begin{gathered}
\pi_{m}(w, A, t)=(1-p)\left(k_{r} \sqrt{a}+k_{m} \sqrt{A}\right) w-A \\
\pi_{r}(p, a)=(1-p)\left(k_{r} \sqrt{a}+k_{m} \sqrt{A}\right)(p-w)-a
\end{gathered}
$$

Theorem 11 ) in the Nash game, manufacturers and retailers the optimal decision is:

$$
p^{N}=\frac{2}{3}, w^{N}=\frac{1}{3}
$$




$$
a^{N}=\frac{1}{324} k_{r}^{2}, A^{N}=\frac{1}{324} k_{m}^{2}
$$

2) In the above Nash equilibrium off his target profit for manufacturers and retailers as well as overall supply chain as follows:

$$
\begin{aligned}
& \pi_{m}^{N}=\frac{1}{162} k_{r}^{2}+\frac{1}{324} k_{m}^{2} \\
& \pi_{m+r}^{N}=\frac{1}{108} k_{r}^{2}+\frac{1}{108} k_{m}^{2}
\end{aligned}
$$

Xie and prove that we will use Neyret (2009) [6] and SeyedEsfahani (2011) [10] in the paper on the way to solving the Nash equilibrium solving them:

$$
p-w \geq w \Rightarrow w \leq \frac{p}{2}
$$

The function shows, the wholesale price up to half the price of zero, the manufacturer's profit will increase the wholesale price increases. Therefore, the manufacturer in order to ensure their own half of the maximum profit, the retail price will be to develop the wholesale price. Retailers seek to profit:

$$
\begin{gathered}
\frac{\partial \pi_{r}}{\partial p}=-\left(k_{r} \sqrt{a}+k_{m} \sqrt{A}\right)(p-w)+\left(k_{r} \sqrt{a}+k_{m} \sqrt{A}\right)(1-p) \frac{\partial \pi_{r}}{\partial a}=\frac{1}{2} \frac{(1-p) k_{r}(p-w)}{\sqrt{a}}-1 \\
\frac{\partial \pi_{r}}{\partial p}=0 ; \quad \frac{\partial \pi_{r}}{\partial a}=0, \quad p=\frac{1}{2} w+\frac{1}{2}, \quad a=\frac{1}{4} k_{r}^{2}(1-p)^{2}(p-w)^{2} \\
w=\frac{p}{2} ; p=\frac{1}{2} w+\frac{1}{2} ; p=\frac{2}{3}, w=\frac{1}{3} \\
\frac{\partial \pi_{m}}{\partial A}=\frac{1}{2} \frac{(1-p) k_{m} w}{\sqrt{A}}-1, \quad \frac{\partial \pi_{m}}{\partial A}=0 ; A=\frac{1}{4} k_{m}^{2} w^{2}-\frac{1}{2} k_{m}^{2} w^{2} p+\frac{1}{4} k_{m}^{2} w^{2} p^{2}
\end{gathered}
$$

\section{B. Stackelberg Game in the Main of Manufacturer}

This game means a manufacturer based Stackelberg game from the master, as the leading manufacturer who decide priorities, retailers followers to make their own decisions based on the best manufacturer's decision. The method of seeking its equilibrium optimal solution uses inverse solution method, which is to find retailers, and then work out the optimal solution manufacturers.

Theorem 2 (1) under Stackelberg game, manufacturers and retailers the optimal decision is:

$$
\begin{gathered}
p^{S M}=\frac{1}{2} w+\frac{1}{2}, t^{S M}=\frac{5 w-1}{3 w+1}, w^{S M}=\frac{4 k_{m}^{2}+\sqrt{16 k_{m}^{4}+9 k_{r}^{4}+16 k_{r}^{2} k_{m}^{2}}}{16 k_{m}^{2}+9 k_{r}^{2}} \\
a^{S M}=\frac{1}{256} k_{r}^{2}(1-w)^{2}(3 w+1)^{2}, \quad A^{S M}=\frac{1}{16} k_{m}^{2} w^{2}(1-w)^{2}
\end{gathered}
$$

(2) In the above Stackelberg equilibrium off his target profit for manufacturers and retailers as well as overall supply chain as follows:

$$
\begin{gathered}
\pi_{r}^{S M}=\frac{1}{128}(1-w)^{3}\left(3 k_{r}^{2} w+8 k_{m}^{2} w+k_{r}^{2}\right) \\
\pi_{m}^{S M}=\frac{1}{256}(1-w)^{2}\left(9 k_{r}^{2} w^{2}+16 k_{m}^{2} w^{2}+6 k_{r}^{2} w+k_{r}^{2}\right) \\
\pi_{m+r}^{S M}==\frac{1}{256}(1-w)^{2}\left(3 k_{r}^{2} w^{2}+10 k_{r}^{2} w+16 k_{m}^{2} w+3 k_{r}^{2}\right)
\end{gathered}
$$




$$
\begin{gathered}
\frac{\partial \pi_{r}}{\partial p}=-\left(k_{r} \sqrt{a}+k_{m} \sqrt{A}\right)(p-w)+(1-p)\left(k_{r} \sqrt{a}+k_{m} \sqrt{A}\right) \quad \frac{\partial \pi_{r}}{\partial a}=\frac{1}{2} \frac{\left(\frac{1}{2}-\frac{1}{2} w\right)^{2} k_{r}}{\sqrt{a}}-1+t \\
\frac{\partial \pi_{r}}{\partial p}=0 ; \quad \frac{\partial \pi_{r}}{\partial a}=0, \quad p=\frac{1}{2} w+\frac{1}{2}, \quad a=\frac{1}{64} \frac{k_{r}^{2}\left(1-2 w+w^{2}\right)^{2}}{(1-t)^{2}} ; \\
\frac{\partial \pi_{m}}{\partial A}=\frac{1}{2} \frac{\left(\frac{1}{2}-\frac{1}{2} w\right) k_{m} w}{\sqrt{A}}-1 ; \quad \frac{\partial \pi_{m}}{\partial t}=\frac{1}{64} \frac{k_{r}^{2}(1-w)^{3}(-5 w+3 w t+1+t)}{(1-t)^{3}} \\
\frac{\partial \pi_{m}}{\partial A}=0 ; \quad \frac{\partial \pi_{m}}{\partial t}=0, \quad t^{S M}=\frac{5 w-1}{3 w+1} ; \quad A^{S M}=\frac{1}{16} k_{m}^{2} w^{2}(1-w)^{2} ; \\
\pi_{m}, \quad \text { Set } \frac{\partial \pi_{m}}{\partial w}=0, \quad w=\frac{4 k_{m}^{2}+\sqrt{16 k_{m}^{4}+9 k_{r}^{4}+16 k_{m}^{2} k_{r}^{2}}}{9 k_{r}^{2}+16 k_{m}^{2}} ;
\end{gathered}
$$

\section{Stackelberg Game Mainly of Retailers}

This game means a method based retailer Stackelberg game from the master, the leader retailer, priority decisions, manufacturer of followers to make their own decisions based on the best decision to retailers. The method of seeking its equilibrium solution uses inverse solution method, which is to find the optimal solution manufacturer, and then work out the optimal solution retailers.

It is easy to find $t=0$, and Nash similar game, with the manufacturer's profit grows, but especially in the next stage, it is difficult to determine the wholesale price as high as the expected value, there is generally a constraint: the manufacturer's profit margin is not greater than profit margins of retailers, like Nash game, we get $w=p / 2$

Theorem 3 (1) under the retailer-led Stackelberg game, manufacturers and retailers the optimal decision is:

$$
t^{S R}=0 ; \quad p^{S R}=\frac{1}{2} ; \quad w^{S R}=\frac{1}{4} ; \quad A^{S R}=\frac{1}{256} k_{m}^{2} ; \quad a^{S R}=\frac{1}{256} k_{r}^{2} ;
$$

(2) In the above Stackelberg equilibrium off his target profit for manufacturers and retailers as well as overall supply chain as follows:

$$
\begin{aligned}
& \pi_{r}^{S R}=\frac{1}{256} k_{r}^{2}+\frac{1}{128} k_{m}^{2} \\
& \pi_{m}^{S R}=\frac{1}{128} k_{r}^{2}+\frac{1}{256} k_{m}^{2} \\
& \pi_{m+r}^{S R}=\frac{3}{256} k_{r}^{2}+\frac{3}{256} k_{m}^{2} \\
& t^{S R}=0, w=p / 2, \frac{\partial \pi_{m}}{\partial A}=\frac{1}{4} \frac{(1-p) k_{m} p}{\sqrt{A}-1,} \quad A=\frac{1}{16}(1-p)^{2} k_{m}^{2} p^{2} \quad \frac{\partial \pi_{r}}{\partial p}=0 ; \quad \frac{\partial \pi_{r}}{\partial a}=0, \quad p=\frac{1}{2} ; \\
& a=\frac{1}{256} k_{r}^{2} ;
\end{aligned}
$$

\section{Cooperative Game}

In this game situation, manufacturers and retailers work together to consider how to maximize the profit of the supply chain. Supply chain profit is mainly dependent on the retail price, local advertising and brand advertising, so the entire decision-making function of the supply chain as follows: 


$$
M \text { ax } \pi_{m+r}=p(1-p)\left(k_{r} \sqrt{a}+k_{m} \sqrt{A}\right)-A-a
$$

Theorem 4 (1), in cooperation with game manufacturers and retailers the optimal decision is:

$$
p^{C}=\frac{1}{2} ; A^{C}=\frac{1}{64} k_{m}^{2} ; a^{C}=\frac{1}{64} k_{r}^{2}
$$

(2) In the above Stackelberg equilibrium off his target profit for manufacturers and retailers as well as overall supply chain as follows:

$$
\begin{gathered}
\pi_{m+r}^{C}=\frac{1}{64} k_{r}^{2}+\frac{1}{64} k_{m}^{2} \\
\frac{\partial \pi_{m+r}}{\partial p}=0, \frac{\partial \pi_{m+r}}{\partial A}=0, \frac{\partial \pi_{m+r}}{\partial a}=0, p=\frac{1}{2}, \quad A=\frac{1}{64} k_{m}^{2}, \quad a=\frac{1}{64} k_{r}^{2} ;
\end{gathered}
$$

\section{Comparative Analysis}

In order to facilitate comparative analysis, we use $k=\frac{k_{m}}{k_{r}}$.

\section{A. Comparison of the Retail Price}

Figure 1, the price comparison in four games under our circumstances, we can find: regardless what value $\mathrm{k}$, the retail price to the retailer and cooperative games led Stackelberg Game-case is minimal, since the cooperative game, the manufacturers and retailers of mutual cooperation, the manufacturer to the retailer lower prices, retailers sell at a lower price.

When the retail price retail price scenario than Nash $\mathrm{k}$ is relatively small, with manufacturers led Stackelberg game situations under small, and when $\mathrm{k}$ is large, the retail price by the manufacturer as the leading case under Stackelberg game is the biggest. This is because when national advertising influence is relatively small, the manufacturer will reduce its investment, wholesale prices decreased, so the retail price will be reduced, whereas empathy.
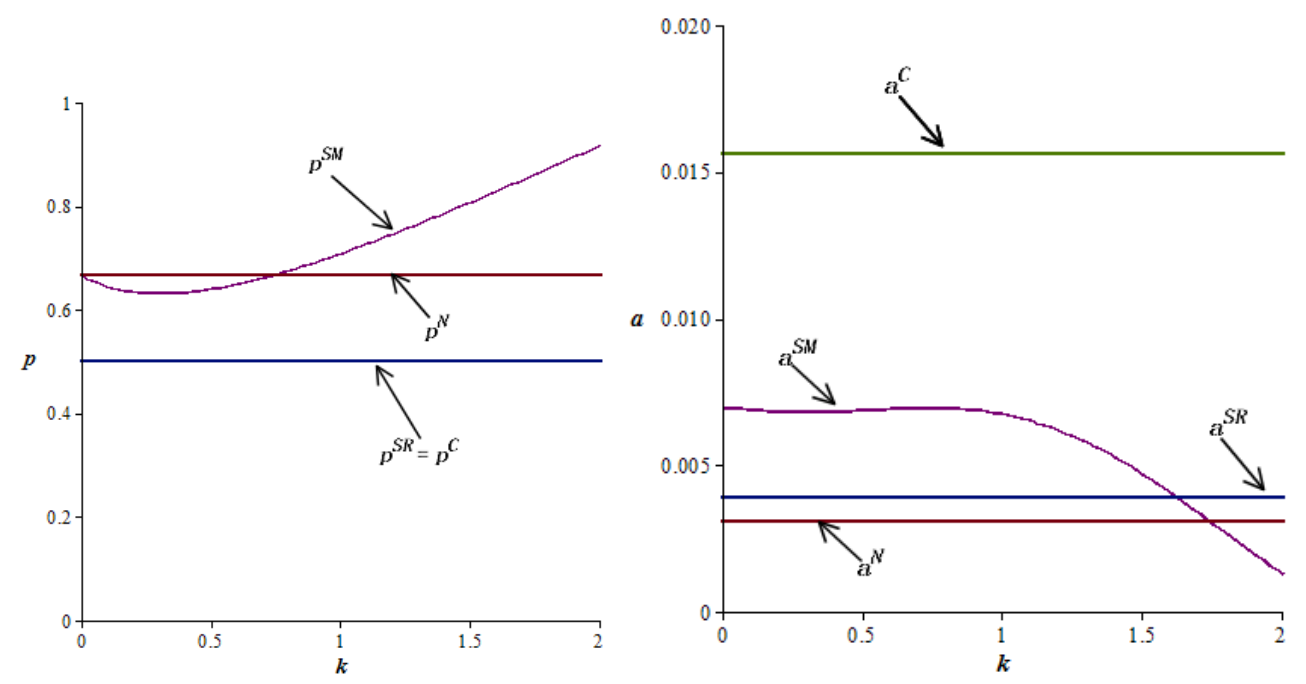

Fig.1

\section{B. Comparison of Local Advertising}

From Figure 2, we compare four local advertising under game situations can be found: No matter what value $\mathrm{k}$ in cooperative game, most retailers local advertising, which is due in the case of 
cooperative game, information sharing, work together to promote their products, so most of the advertising investment.

When $\mathrm{k}$ is small, local advertising Nash game situations under minimum investment; and when $\mathrm{k}$ is large, at least investment is led by the manufacturer Stackelberg game situation. Because when the influence of local advertising is relatively large, local advertising investment is relatively large, with the reduction of its influence, its investment will also be reduced.

\section{Comparison of National Advertising}

Figure 3, we compare these four national advertising game situations can be found: k regardless of what value, in national advertising cooperative game under the most investment, which is due to the two sides to cooperate in information exchange, concerted marketing so most of the advertising investment. To retailers led Stackelberg game situation followed. But advertising in the manufacturer-led Stackelberg Game-case input size will vary k varies, this is because when the dominant party game manufacturer will influence national advertising as well as advertising costs adjust its investment.
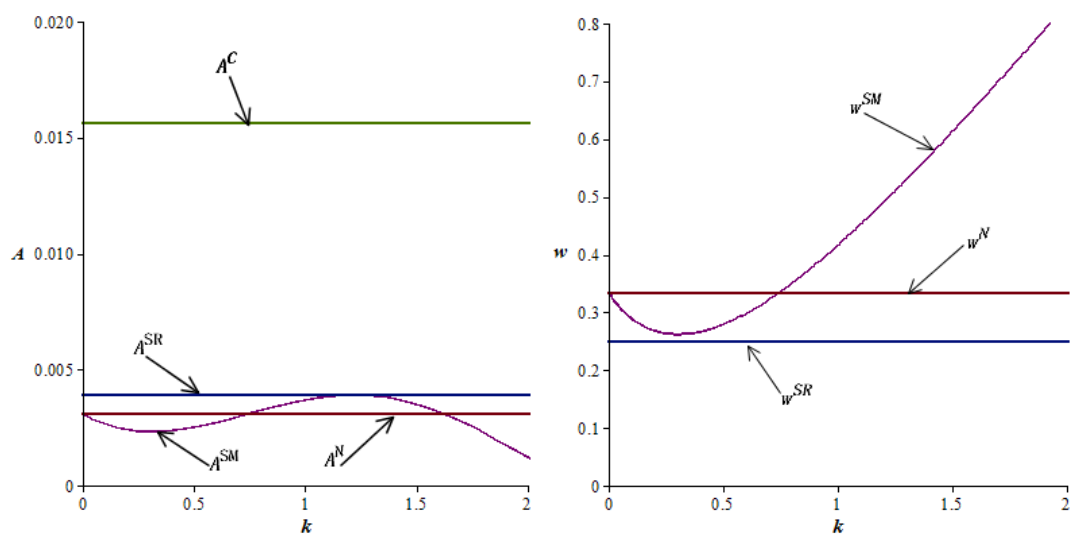

Fig. 2

\section{Comparison of Wholesale Price}

From Figure 4, we compare the three wholesale price game situations can be found: no matter what value $k$, the wholesale price to retailers led Stackelberg Game-case is minimal, because the retailer is leader, we will negotiate with the manufacturer, the wholesale price down. When $\mathrm{k}$ is small, wholesale pricing Nash Game-case is the largest, and vice versa is at the leading manufacturer of the largest Stackelberg game situation, this is because when national advertising influence is relatively small, the manufacturer compares their investment less, resulting in lower wholesale prices.

\section{E. Comparison of Retailer Profits}

From Figure 5, by retailer profits comparing three cases under apparent: when $\mathrm{k}$ is relatively small, when the retailer to the manufacturer led Stackelberg game situations biggest profits, on the contrary, is the largest retailer own profit-oriented the Stackelberg game situation. This is because in order leading manufacturer of game situation, when local advertising influence large retailers put more of their sales increase, increase profits, but the influence is relatively small local advertising, retailers its small investment, sales also fell, profit decreases. 

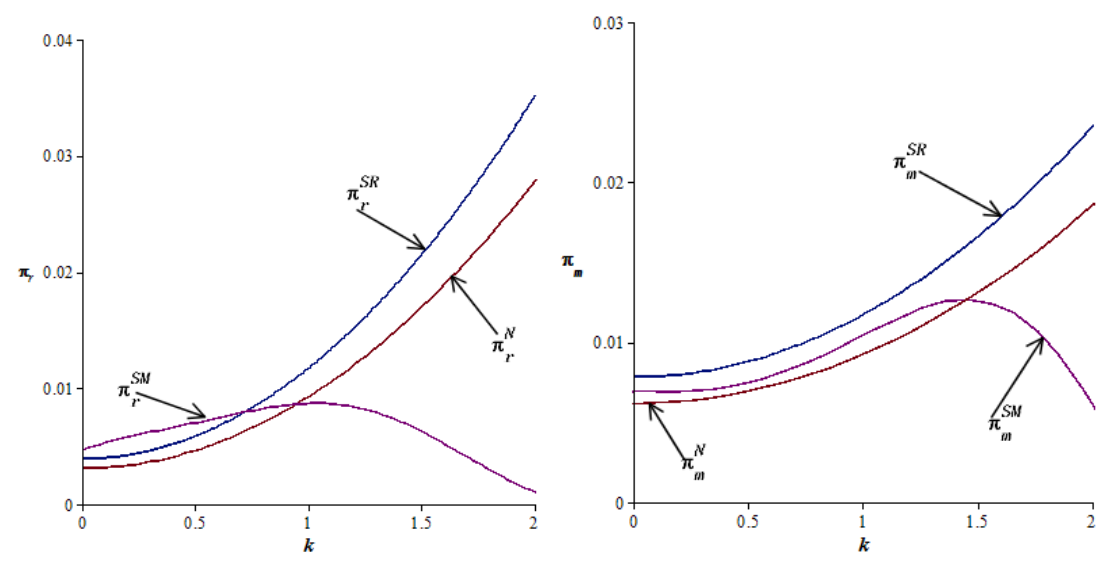

Fig. 3

\section{F. Comparison of the Manufacturer Profits}

Figure 5, the manufacturer's profit by contrasting with the three game scenarios, we can see: no matter what value $\mathrm{k}$, the profits of the largest manufacturing when retailers led Stackelberg game situation, which is due when the leading retailer, investment of its multi-national advertising, in this case lower than when the leading manufacturer in the case of the retail price, high-volume, small profits, big profits. When $\mathrm{k}$ is small, Nash game situation makes the manufacturer's profit minimum, on the contrary, when the manufacturer led Stackelberg game minimum profit situation. This is because when national advertising influence is relatively small, its ad spending reduced, decreased sales, followed by profits minus 3.7 Comparison of the overall channel profits

Figure 6, the overall profit margin of four games under the circumstances, we can see: no matter what value $\mathrm{k}$, the overall maximum profit under cooperative game, which is due to cooperative game, manufacturers and retailers are the most advertising investment the retail price is the lowest, to maximize sales, profits are maximized. When $\mathrm{k}$ is relatively small, the overall profit Nash Game-case minimum; on the contrary, under the Manufacturing led Stackelberg game situation overall profit minimum, this is because of the influence of reduced national advertising, manufacturers reduced their investment small, overall sales decreased, resulting in reduced overall profit channels.

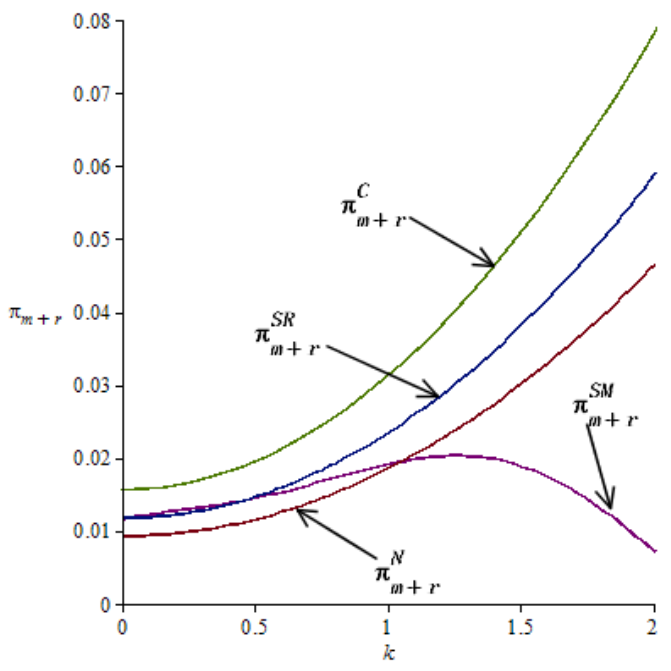

Fig. 4 


\section{Conclusion}

In the case of a static manufacturer and a retailer, we analyzed and compared the case of cooperation under the four game advertising and product pricing. The study found: In the cooperative game, put on local advertising and national advertising of the highest, at a time when the development of the retail price of the lowest; in order to retailers led Stackelberg game situation, the manufacturer of the highest profits; and retail the size of the profits of national advertising and local advertising impact factors related; overall channel profits in the largest cooperative game. So the manufacturers, retailers and channel Overall, cooperation is better than non-cooperative game strategy game strategy. Follow-up study will investigate the case of many of the behavioral economics or fairness preference theory taking into account the cooperation advertising.

\section{REFERENCE:}

[1] Xie J, Wei JC. Coordinating advertising and pricing in a manufacturer-retailer channel. [J].European Journal of Operational Research, 2009, 197(2):785-791.

[2] Jorgensen, S., \& Zaccour, G. (1999). Equilibrium pricing and advertising strategies ina marketing channel. Journal of Optimization Theory and Applications, 102(1),111-125.

[3] Jorgensen, S., \& Zaccour, G. (2003). A differential game of retailer promotions.Automatica, 39(7), $1145-1155$.

[4] Jorgensen, S., Sigue, S. P., \& Zaccour, G. (2001). Stackelberg leadership in a marketingchannel. International Game Theory Review, 3(1), 13-26.

[5] Yue J., J. Austin, M.C. Wang, Z.M. Huang .Coordination of Cooperative Advertising in a Two-Level Supply Chain When Manufacturer Offers Discount[J].European Journal of Operational Research, 2006, 168: 65- 85.

[6] XieJ., Neyret A. Co-op advertising and pricing models in manufacturer-retailer supply chains. Computers \& Industrial Engineering, 2009, 56(4):1375-1385.

[7] KarrayS, GZaccour. Could co-op advertising be a manufacturer's counterstrategy to store brands? [J]. Journal of Business Research, 2006, 59:1008-1015.

[8] Sigué, P.S., P. Chintagunta. Advertising strategies in a franchise system [J]. European Journal of Operational Research, 2009, 198:655-665.

[9] He, X., A. Krishnamoorthy, A. Prasad, S.P. Sethi. Co-op advertising in dynamic retail oligopolies [J]. Decision Science, 2012, 43(1): 73-105.

[10] Seyed Esfahani, M.M., M. Biazaran, M. Gharahhani. A game theoretic approach to coordinate pricing and vertical co-op advertising in manufacturer-retailer supply chains [J]. European Journal of Operational Research, 2011, 211: 263- 273. 